\title{
Preliminary Evaluation of Potassium Extraction from Bamboo Ash
}

\author{
Tjokorde W. Samadhi ${ }^{1,{ }^{*}}$, Febrizca Narcia $^{1}$, and Hendro Amril ${ }^{1}$ \\ ${ }^{1}$ Faculty of Industrial Technology, Institut Teknologi Bandung, Jalan Ganesha 10 Bandung 40132, Indonesia
}

\begin{abstract}
Bamboo is a potentially economical fuel crop that has not been utilized at a substantial extent for energy generation in Indonesia. As a thermal conversion waste, bamboo ash is particularly interesting due to its high potassium content. This paper discusses the determination of several key parameters of a simple batchwise extraction process to recover potassium in the form of weak solution from bamboo ash. To produce the ash, black bamboo (Gigantochloa atroviolaceae) is charred in a fixed bed combustor. The bamboo char is ground and ashed at $500{ }^{\circ} \mathrm{C}$ in an electric furnace. The ash yield is $3.3 \%$-mass relative to as-received ash, with an ash $\mathrm{K}_{2} \mathrm{O}$ content of $12.9 \%$-mass. The ash is ground until passing 100-mesh standard sieve, and extracted by deionized water on a 2-stage laboratory-scale batchwise extractor battery. Process variables include extractror battery configuration (counter-current and co-current), temperature (nominal setting at $45-80^{\circ} \mathrm{C}$ ), and contact period of 1-6 hours. The concentration of extracted $\mathrm{K}_{2} \mathrm{O}$ increases asymptotically with temperature and contact time. Counter-current extraction yields more than twice the extract $\mathrm{K}_{2} \mathrm{O}$ concentration compared to cross-current extraction. The optimum conditions for the counter-current extraction is identified as a temperature of $78{ }^{\circ} \mathrm{C}$ and contact time of 4 hours, resulting in a $0.70 \%$-mass $\mathrm{K}_{2} \mathrm{O}$ solution concentration. Spot sampling of commercial liquid fertilizer products in Indonesia indicates an equivalent $\mathrm{K}_{2} \mathrm{O}$ content of 0.08 $13.6 \%$-mass, suggesting the potential of the bamboo ash extract as an intermediate for fertilizer product.
\end{abstract}

\section{Background}

As the current near- to intermediate-term energy policy of the Indonesian government calls for a $5 \%$ contribution of renewable energy sources by the year 2025, it is expected that the production of biomass shall increase substantially in the coming years. With this increase in ash waste volume, it is naturally expected that biomass ash utilization shall also become an increasingly urgent issue for the nation.

Among the widely distributed plants in Indonesia, bamboo is still largely overlooked as a potential energy crop. This potential is driven by its relatively fast growth, and its heating value which is nearly comparable to hardwood. Its poor compostability makes it attractive for thermal conversion processes [1, 2].

As reported by various authors, bamboo stalk ash exhibits a particularly high potassium content relative to other biomass types [2-4]. While the total ash content of bamboo stalk is not particulary high at 1-6\%-mass [1], the high potassium content nevertheless suggests that bamboo ash may serve as an economically viable source of potassium. Works on potassium extraction from biomass ash have been reported in the literature. Wood ash is of course the earliest biomass ash to be exploited for alkali production [5]. Other biomass have also been studied, including wheat straw [6], corn straw [7], banana peels [8], and others. Published works on potassium production from bamboo ash is at best scarce.

This work describes the valorization of bamboo ash through simple, batch-wise, laboratory scale potassium extraction process. As a preliminary work, the objective of this study is to assess the extractability of potassium from bamboo ash with a simple process, and to evaluate the technical feasibility of the extract product for use as a fertilizer intermediate.

\section{Experimental}

The bamboo species selected for this study is the black bamboo (Gigantochloa atroviolaceae) obtained from local markets in the Bandung area. The bamboo stalk is cut into thin strips roughly $10 \mathrm{~cm}$ long, and charred in a simple fixed-bed combustor with natural convection. The bamboo char is then pulverized with mortar and pestle, and ashed in an electric furnace at $500{ }^{\circ} \mathrm{C}$. The obtained ash is then sieved to 100 -mesh and stored in a sealed container at ambient condition. The total

\footnotetext{
*Corresponding author: twsamadhi@che.itb.ac.id
} 
potassium content of the ash is determined by dissolving all extractables in concentrated nitric acid solution followed by filtration, dilution, and measurement by atomic absorption spectroscopy (AAS).

The extraction is undertaken using 3-neck glass flasks as batch extractors, with deionized water as the solvent. Solid-liquid contact is facilitated by a mechanical stirrer. Two glass beakers are arranged as an extraction battery that can operate in cross-current and counter-current modes alternatively. Contact patterns between solid and liquid flow in these configurations are described in Figures 1 and 2. After the desired contact time is achieved, the stirrer is powered down, the extraction mixture is allowed to settle, and the clear extract is separated by decantation.

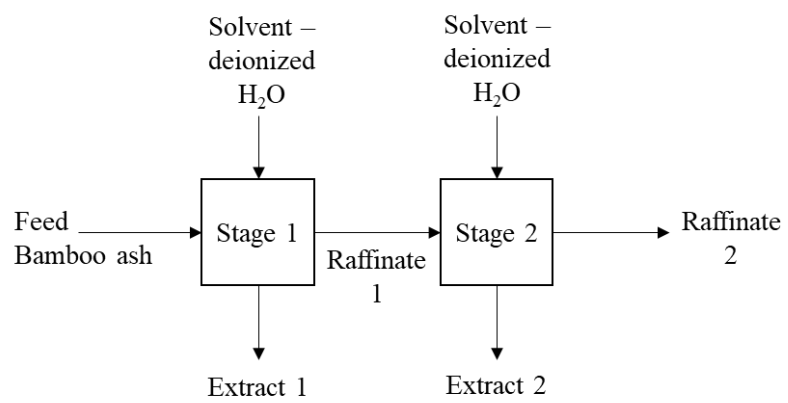

Fig. 1. Materials flow pattern in the cross-current extraction battery configuration.

Based on the total ash feed mass of 33 grams and total extractable $\mathrm{K}_{2} \mathrm{O}$ content of $12.9 \%$-mass on dry ash basis, the total amount of $\mathrm{K}_{2} \mathrm{O}$ fed into the extraction battery is $4257 \mathrm{mg}$. As the numbers in Figure 5 indicate, the total mass of $\mathrm{K}$ in the combined extract product streams of the cross-current extraction battery is $898 \mathrm{mg}$ (equivalent to $1082 \mathrm{mg} \mathrm{K}_{2} \mathrm{O}$ ), which implies that approximately $25.4 \%$ of the total $\mathrm{K}$ is extracted. The $\mathrm{K}_{2} \mathrm{O}$ concentration in the combined extract product is approximately $0.30 \%$-mass.

In the cross-current extraction, product streams Extract \#1 is expected to contain higher $\mathrm{K}$ concentration than Extract \#2. Both of these streams are mixed into the final extract product. In the counter-current extraction, the process is repeated in three cycles until a steady batchwise process is achieved. At this steady state, the concentrations of the extract product streams are equal. To ensure data consistency however, these product streams are also mixed before analyzed for the $\mathrm{K}$ concentration.

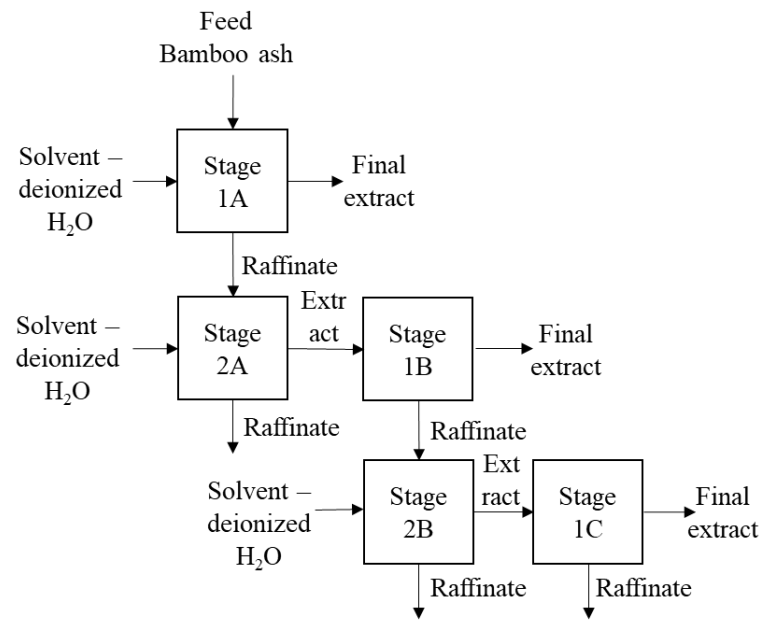

Fig. 2. Materials flow pattern in the counter-current extraction battery configuration.

Experimental variables are varied in an exploratory manner. The extraction temperature is varied in the 45$80^{\circ} \mathrm{C}$ range, both the cross-current and counter-current flow configuration are tried, and the contact time is varied in the 1-6 hours range. Potassium content in the extract is measured by AAS.

\section{Results and discussion}

\subsection{Temperature and time determination}

Mass balance calculations over the entire bamboo combustion and ashing steps indicate an ash content of $3.3 \%$-mass on dry raw bamboo basis, consistent with the range of values reported in the literature [2]. Total extractable potassium measured by $\mathrm{HNO}_{3}$ dissolution is $12.9 \%$-mass (as $\mathrm{K}_{2} \mathrm{O}$ ) relative to total ash. This value is substantially lower than those reported in the literature, suggesting that the removal of potassium by the acid solution may not be complete, or that the bamboo stalk specimen is of old age, which has been reported to be accompanied by a decrease in its potassium content [9] Since this study is focused more on the relative extractability of the potassium rather than the absolute amount of the extracted material, potential inaccuracy in the total extractable potassium measurement is not considered to be a critical problem.

The first part of the ash extraction experiment addresses the effect of temperature on potassium extractability. Figure 3 presents the $\mathrm{K}$ concentration in the extract product of a single-stage batch extraction of the bamboo ash at 45,60 , and $78{ }^{\circ} \mathrm{C}$. While the set point of the latter temperature is $80{ }^{\circ} \mathrm{C}$, the actual measured temperature is $78{ }^{\circ} \mathrm{C}$. Two replicate experiments are run at each temperature; $95 \%$ confidence intervals of the average $\mathrm{K}$ concentration at each temperature are included. 


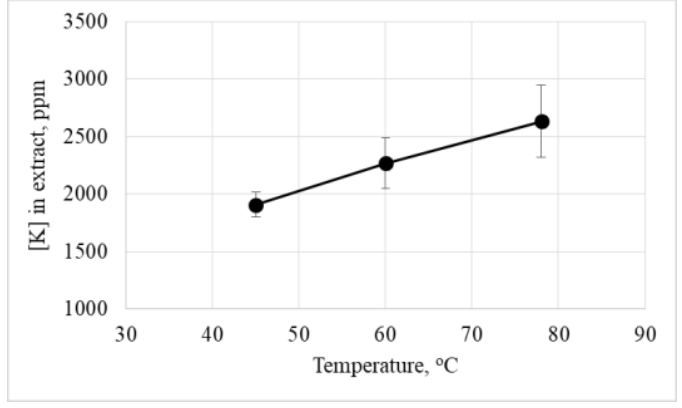

Fig. 3. Effect of temperature on K extractability

Figure 3 clearly indicates the statistically significant increase in $\mathrm{K}$ extraction with temperature in the $40-80{ }^{\circ} \mathrm{C}$ range. To avoid excessive loss of solvent, subsequent experiments are run at a temperature set point of $80^{\circ} \mathrm{C}$.

In the second extraction experiment, bamboo ash is extracted in a single-stage batch extractor at nominal temperature set point of $80{ }^{\circ} \mathrm{C}$, and contact time varied in the 0.5-6.0 hours range to determine a practical contact time within which the phase equilibrium between extract and raffinate streams has been approached. Two feed to solvent mass ratios are selected, namely 1:5 and 1:250, to assess the presence of mass transfer limitations.

Figure 4 plots the extracted $\mathrm{K}$ concentrations against contact time for the two solid/liquid ratios. Incremental gradients between successive time values are computed. The overall trend of extracted $\mathrm{K}$ concentration vs. time is similar for both solid/liquid ratios, in which an acceptably low concentration gradient starts to be achieved at contact time between 4 and 5 hours. Therefore, a contact time of 4 hours is selected for subsequent experimental runs.

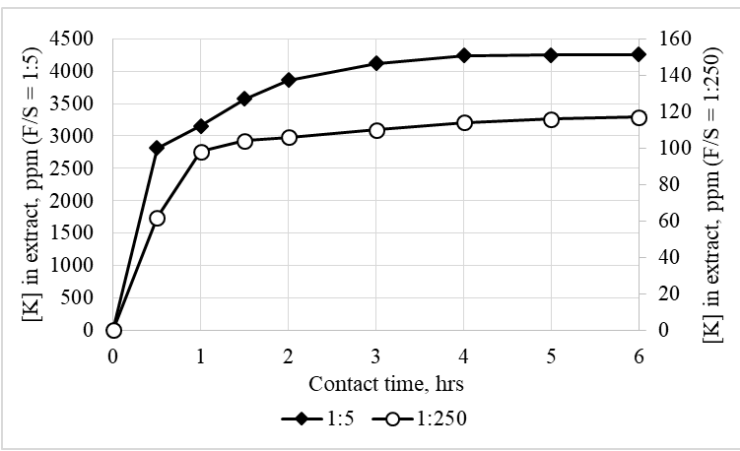

Fig. 4. Extracted $\mathrm{K}$ concentrations as functions of contact time at $80{ }^{\circ} \mathrm{C}$, for ash feed to water solvent mass ratios of 1:5 ( and $1: 250(\mathrm{O})$.

\subsection{Two-stage extraction}

In the final experiment, bamboo ash is extracted in a two-stage batchwise extraction in cross-current and counter-current configurations. Based on the preceding experiments, the extraction temperature is set at $80{ }^{\circ} \mathrm{C}$ and contact time at 4 hours. The ash feed mass is 33 grams. The fresh solvent volume is set such that in each extraction stage the fresh feed or raffinate is mixed with $250 \mathrm{~g}$ of solvent. The solvent is divided into two parts of 250 grams, each for one extraction stage. Figures 5 and 6 describes the overall mass balance of the two extraction batteries.

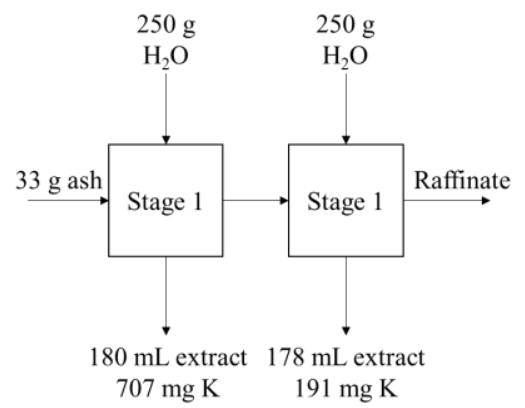

Fig. 5. Overall mass balance of the cross-current 2-stage extraction of bamboo ash.

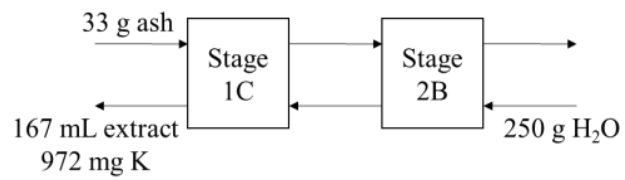

Fig. 6. Overall mass balance of the counter-current 2-stage extraction of bamboo ash

In the counter-current extraction battery, extract from stage 1B (refer to Figure 2 for the designation of the stages) is collected as the final product. This stream contains $972 \mathrm{mg}$ of $\mathrm{K}$ (equivalent to $1171 \mathrm{mg}$ of $\mathrm{K}_{2} \mathrm{O}$ ) dissolved in $167 \mathrm{~mL}$ of extract product. Therefore, the extracted $\mathrm{K}$ is approximately $27.5 \%$ of the total extractable $\mathrm{K}$ in the ash. The $\mathrm{K}_{2} \mathrm{O}$ concentration in the final extract is approximately $0.70 \%$-mass, more than twice the concentration produced by cross-current extraction.

To evaluate the characteristics of the bamboo ash extract solution as a potential precursor for fertilizer, spot sampling of commercial organic or NPK fertilizer available in local supermarkets in the Bandung area has been undertaken. Two fertilizer brands were identified, namely Magicgro and GA Premium. The first brand, which is advertised as a liquid organic ready-to-use fertilizer contains $0.08 \%-\mathrm{K}_{2} \mathrm{O}$. The latter brand, which is advertised as a liquid NPK fertilizer, contains $13.6 \%$ $\mathrm{K}_{2} \mathrm{O}$.

The K concentration of the bamboo ash extract lies in between these two commercial products. Therefore, the bamboo extract is a promising source of potassium for fertilizer. It can be mixed with other macro- and micronutrients to produce ready-to-use liquid organic fertilizer, or concentrated further to render it useful as an NPK fertilizer component.

Both the cross-current and counter-current extraction configurations are able to produce extract with promising $\mathrm{K}$ concentrations. Therefore, the choice between these flow configurations is likely to be determined by the suitability of each process to the scale of production. Cross-current extraction is simpler to operate and consumes less ash for small-scale batch production. Counter-current extraction exhibits higher 
separation efficiency, but is more suitable for larger scale continuous production.

\section{Conclusions}

A potential route for biomass ash valorization has been identified, which involves the recovery of potassium from bamboo ash through extraction process using water as the solvent. A simple laboratory-scale two-stage batchwise extraction battery is able to recover approximately $25-28 \%$ of the total extractable potassium from a black bamboo (Gigantochloa atroviolaceae) ash. Favorable process conditions include an extraction temperature of $78{ }^{\circ} \mathrm{C}$, contact time of 4 hours and solid to liquid mass ratio of 1:5 - 1:7.5 for each extraction stage. The simple batchwise extraction battery process is able to produce extract with $\mathrm{K}$ concentration of 0.25 $0.58 \%$. This concentration range compares well to commercial liquid fertilizder products, suggesting that bamboo ash is an attractive source of water-extractable potassium for fertilizer production.

This research is funded by the P3MI grant program for the Chemical Engineering Product Design and Development Expertise Group at the Faculty of Industrial Technology, Institut Teknologi Bandung.

\section{References}

1. B. Engler, S. Schoenherr, Z. Zhong, G. Becker, Int. J. Forest Eng. 23, 2 (2012)

2. J.M.O. Scurlock, D.C. Dayton, B. Hames, Biomass Bioenerg. 19, 4 (2000)

3. S.V. Vassilev, D. Baxter, L.K. Andersen, C.G. Vassileva, Fuel 89 (2010)

4. T.W. Samadhi, F.G. Gumilar, K.F. Ramadani, Key Eng. Mat. 709 (2016)

5. M.S. Erich, J. Environ. Qual. 20, 3 (1991)

6. Y. Wang, W. Wang, H. Tan, W. Du, X, Qu, Environ. Prog. Sustain. 34, 2 (2015)

7. X. Wang, S. Wang, X. Zhao, W. Li, C. Dong, L. Zhao, Adv. Mater. Res. 860-863 (2014)

8. I.O. Olabanji, E.A. Oluyemi, O.S. Ajayi, Afr. J. Biotechnol. 11, 99 (2012)

9. X.B. Li, T.F. Shupe, G.F. Peter, C.Y. Hse, T.L. Eberhardt, J. Trop. For. Sci. 19, 1 (2007) 